\title{
The dark side of friendship: envy*
}

\author{
Natalia Jiménez \\ University of Alicante and University of Granada \\ Ramón Cobo-Reyes \\ University of Granada
}

April 3, 2008

\begin{abstract}
This paper studies the effect of social relations on the convergence to the efficient equilibrium in a $2 \times 2$ coordination game. We employ a $2 \times 2$ factorial design in which we explore two different games with asymmetric payoffs and two matching protocols: "friends" versus "strangers". In the first game payoffs of the worse off player are the same in the two equilibria, whereas in the second game, this player must sacrifice her own payoff for achieving the efficient equilibrium. Results show that "strangers" coordinate more frequently in the efficient equilibrium than "friends" in both
\end{abstract}

*I am very grateful to Pablo Brañas-Garza, Ramón Cobo-Reyes and Giovanni Ponti for their constant support and interest in the project. I would like to thank Laura Crespo, Teresa García, Elena Martinez, Juan Mora, Ana Moro and Carlos Sánchez for their irreplaceable help in the econometrics. Financial support is gratefully acknowledge by the Generalitat Valenciana GV 06/275 , Spanish Ministry SEJ2007-62081/ECON and Junta de Andalucia SEJ-2547. 
games. Regarding network measures, (such us degree in, degree out and betweenness) they are all positively correlated with the strategy which leads to the efficient outcome except clustering. In addition, envy is a salient factor in explaining efficient convergence.

Keywords: coordination, efficiency, envy, experiments, friendship, social networks.

JEL Class.: A14, C72, C92, D63.

\section{Introduction}

There exists a growing interest on how group identity and social distance can influence subjects' behavior in different economic environments. In fact, in many laboratory experiments, participants can see each other before, during and after the experiment and may well be friends or acquaintances. Obviously, this physical and emotional proximity of the experimental subjects may affect individuals' behavior. Group identity has been explored in the experimental literature in different ways. Some authors (Brown-Kruse and Hummels (1993), Cadsby and Maynes (1998)) introduce a previous questionnaire where the information is shared with the rest of the subjects as to create a "sense of membership" among individuals in a group. Kirkwood and Solow (2002) run an experiment with groups comprised of members of an already-existing group - the Iowa Marching Band. They find that the higher the social identity, the higher are contributions in the Voluntary Contributions Mechanism. ${ }^{1}$

\footnotetext{
${ }^{1}$ The Voluntary Contributions Mechanism is a Public Good game in which contributions are solicited by a central agent and the level of public good provided is determined by the
} 
Croson, Mark and Snyder (2003) use fraternities and sororities memberships as experimental subjects. They show that creating a sense of group identity among women increases efficiency and equity in public goods games but this group identity among men decreases these measures.

In the Ultimatum Game context, Henrich (2000) shows that subjects from Machichuenga communities are willing to accept very low offers. Brañas-Garza, Cobo-Reyes and Dominguez (2006a) find similar results for gypsies from a Spanish community. Those results seem to support the idea that group identity can lead to a more efficient outcome. ${ }^{2}$

Despite some contributions regarding anonymity (see Hoffman, McCabe, Shachat and Smith (1994), Hoffman, McCabe and Smith (1996) and Bohnet and Frey (1999)), the existent economic literature on the measure of social distance is very scarce. ${ }^{3}$ Recently, some authors are using social networks to properly analyze the role of social distance. Leider, Mobius, Rosenblat and Quoc-Ahn (2006) analyze the effect of "friendship" in donations in Dictator Games, illustrating that dictators give more to "friends". Brañas-Garza, Duran and Espinosa (2005) replicate this result under weaker conditions, dictators know that the recipient will be a friend with a certain probability. Also, BrañasGarza et al. (2006) find that giving is positive correlated to "social integration" (measured as betweenness centrality). Goeree et al (2007) find that giving is

\footnotetext{
sum of these contributions.

${ }^{2}$ Subjects from the same community are ready to accept very unequal distributions while results in the Ultimatum Game with strangers show that offers below 20 percent are more likely to be rejected (diminishing the efficiency of the outcome).

3 The term "social distance" is defined by the Encyclopedia of Psychology (2000) as "the perceived distance between individuals or groups".
} 
inversely proportionate to the network distance between dictator and recipient. These studies, which use not only group belonging but also the architecture of relationships, indicate that altruism increases with "friendship".

This paper uses recent experimental devices to elicit social networks to explore strategic situations which, as far as we know, have not been yet analyzed in the economic literature. Specifically, this paper tries to analyze the effect of "friendship" in the outcome obtained in a coordination game.

In games with a unique Nash equilibrium, each player should have no difficulty conjecturing his opponents' actual moves (from a theoretical perspective). However, in games with multiple Nash equilibria, agents may have difficulty conjecturing the behavior of others. To solve this problem subjects require coordination. Miscoordination can lead to inefficiencies that are hard to reverse. Many approaches to the selection problem have been used. One approach is to look at features of equilibria and choose those that are desirable, for example those which are payoff dominant equilibrium (see Harsanyi and Selten, 1988). A second approach is to ask which equilibria are more likely to be reached by adaptation or evolution (see Fudenberg and Levine, 1998). The third one tries to infer what selection principles players are using by putting them in experiments and observing what they do (see Van Huyck, Battalio and Beil, 1990 or Van Huyck, Battalio and Rankin, 1996).

This paper goes one step further in the analysis of coordination games in two different ways. On one side, we analyze how relations established by individuals in a social network may influence the sort of equilibrium subjects converge to, 
when efficiency is confronted with equality (or self interest). On the other side, we study the effect of the standard measures of social networks on the probability of playing the strategy which leads to the efficient outcome.

To this aim, we propose a two step experiment. For the first step, we use the Brañas-Garza et al. (2006b, BCJP hereafter) mechanism to elicit the latent social network. Once the social connections are obtained, in a second step, a coordination game is conducted.

We explore two different games:

i) Players face a coordination game with two different equilibrium payoffs. The first one is efficient but payoffs of the row player are double than those of the column player. ${ }^{4}$ The second equilibrium is egalitarian, that is, both players have the same payoffs. This game states a trade-off between an egalitarian and an efficient outcome.

ii) As in coordination game $i$ ), in the second there is an efficient equilibrium in which payoffs of the row player are double than those of the column player. However, in the second equilibrium, payoffs of the column player are higher than those of the row player. Thus, the column player must sacrifice her payoff to achieve the efficient equilibrium.

The above literature on social networks and group identity illustrates the positive effect of individual behavior on social "values" such as altruism, equity, fairness and so on, that is, other regarding preferences in positive aspects.

This paper adds two counterexamples of the above literature. Our results

\footnotetext{
${ }^{4}$ In this paper, efficiency is measured based on the theory of the transferable utility, that is maximizing the sum of individual payoffs.
} 
show that:

i) Friends coordinate at the efficient equilibrium in $60 \%$ of the cases, that is, a situation in which Player 2 accepts to earn half of Player 1 (his/her friend). Surprisingly, strangers coordinate at this equilibrium in $100 \%$ of the cases.

ii) When subjects have the possibility to alternate in order to reduce inequality (in the second game since each player is better off in a different equilibrium), friends miscoordinate in $46 \%$ of the cases, whereas strangers do only in $28 \%$ of cases.

One feasible explanation for these results is envy. It is sensitive to think that this factor is more important among peers than among strangers. To study if this reasoning is valid, we design an additional step in the experiment in which we obtain an envy index for each subject. Afterward, we develop an econometric analysis on the effect of social networks measures, the envy index and some sociodemographic variables (obtained through a questionnaire after the experiment) on the achievement of the efficient equilibrium. We find that most network measures are significant. Those related to social integration as degree and betweenness affect positively the efficiency, while the effect of clustering is negative. As regards envy, it has a negative and highly significant effect on efficiency. Moreover, this effect is higher for "friends" than for "strangers". Finally, sociodemographic variables are overall not significant.

The rest of the paper is organized as follows: section 2 describes the experimental design and research hypothesis. Results are presented in section 3. Finally, section 4 concludes. 


\section{Experimental design}

The experiment was conducted in three stages.

\subsection{First stage: BCJP}

In the first stage, subjects participate in the elicitation mechanism suggested by BCJP and revealed their friends. In this mechanism, subjects are invited to reveal their friends' names, together with a valuation (from 1 to 4 ) measuring the strength of the relationship. According to the mechanism, subjects are rewarded with a fixed price either a) if a randomly selected link is bidirectional and if the strengths corresponding to this link are sufficiently close or b) if they do not name anybody. In this step, experimental subjects did not know that they were going to play a new game after the elicitation (several days later).

\subsection{Second stage: coordination games}

In the second stage, subjects played a 2-player coordination game were the most salient feature was that we controlled the matching: friends versus strangers. We designed two alternative payoff tables (see Figure 1). 


\begin{tabular}{c|c|c|}
\multicolumn{1}{c}{} & \multicolumn{1}{c}{$\mathbf{L}$} & \multicolumn{1}{c}{$\mathbf{R}$} \\
\cline { 2 - 3 } $\mathbf{U}$ & 8,4 & 3,3 \\
\cline { 2 - 3 } $\mathbf{D}$ & 7,3 & 4,4 \\
\hline
\end{tabular}

Game 1

\begin{tabular}{c|c|c|}
\multicolumn{1}{c}{} & \multicolumn{1}{c}{$\mathbf{L}$} & \multicolumn{1}{c}{$\mathbf{R}$} \\
\cline { 2 - 3 } $\mathbf{U}$ & 8,4 & 2,2 \\
\hline $\mathbf{D}$ & 7,3 & 3,5 \\
\hline
\end{tabular}

Game 2

Figure 1. Games structure.

Each game analyzes a different sort of conflict of interests. First payoff table in Figure 1 corresponds to Treatment 1 (Game 1). This table proposes a coordination game where two possible equilibria arise, $(\mathrm{U}, \mathrm{L})$ and $(\mathrm{D}, \mathrm{R})$. Those equilibria are conflicting in the following sense: while in equilibrium $(D, R)$ subjects's payoffs are equal, in equilibrium (U, L) subjects' payoffs are unequal but the equilibrium is more efficient. That is, the column player has to sacrifice (at a zero cost) equity in order to obtain an efficient outcome. However, in Treatment 2 (Game 2) the column player must sacrifice her payoff to achieve the efficient equilibrium. In this sense (and from column player's view), we may consider that (U, L) is a "costly" efficient equilibrium in Treatment 2 but a "costless" efficient equilibrium in Treatment 1.

The asymmetry of the games is due not only to the fact that there is only one efficient equilibrium, but also because we avoid other features which may introduce some noise in the analysis of the results: 
i) Risk dominant equilibria. ${ }^{5}$ Some experimental results give evidence that players are influenced by the risk dominance characteristics of games. ${ }^{6}$ Thus, the design of the experiment seeks to avoid the existence of risk dominant equilibria. $^{7}$

ii) Strategic uncertainty. We reduce this effect by making that the maximum and minimum payoffs players can obtain with each strategy do not differ in more than 1 experimental unit so, the problem of players choosing a particular strategy because they assure higher expected payoffs practically disappears.

In all treatments, the roles for player 1 and 2 were randomly assigned and also, subjects were assigned randomly to a particular treatment (game 1 or 2). There were 25 rounds in each treatment. Matching and the role of the player were fixed throughout the session. After each round, information about the strategy played by their partners, own payoffs in the current round and own cumulative payoffs was provided. At the end of the 25 rounds, payoffs were computed and participants were paid in a private way.

For each treatment, six sessions were run in which participants were "friends" (obtained with the above mechanism) and another six sessions with "strangers". Information about the matching was provided at the beginning of the experiment. In the "friends" protocol, participants only know that they were playing with a fixed friend, but not which specific friend (see next subsection 2.2.1). No

\footnotetext{
${ }^{5}$ We consider risk dominant equilibria in the sense of Harsanyi and Selten (1988).

${ }^{6}$ See for example Schmidt, Shupp, Walker and Ostrom (2003).

${ }^{7}$ As a consequence, the only Nash equilibrium in mixed strategies for both games is $\left(\left(\frac{1}{2}, \frac{1}{2}\right),\left(\frac{1}{2}, \frac{1}{2}\right)\right)$, that is playing each strategy at random with equal probability, independently of the role of the player.
} 
one was allowed to participate in more than one session. We conducted twelve sessions at the University of Granada with 14-18 participants per session. Subjects were recruited from a public call for voluntary participation. On average, each person earned 4 Euros for the first stage and 14 Euros for the second stage (one-hour session). Our experiment was programmed using the z-tree software (Fischbacher 2007). ${ }^{8}$

\subsubsection{Matching}

Using the map of social connections, subjects were matched for playing in the second stage according to the following rule. For the "friends" protocol, even groups of people who had named each other were matched together in pairs. We try that most groups of friends (extracted from the previous elicitation mechanism) were at least composed of 4 people to avoid reciprocity after the experiment. The idea was that subjects were playing with a friend but they did not know which specific friend. They could only infer that the probability of being playing with one particular friend was $\frac{1}{n-1}$, where $n$ is the number of components in the group of friends. However, this was not always possible (because we needed bidirectional links to avoid deception), so we had 12 subjects who knew exactly who was his/her pair. ${ }^{9}$

For the "strangers" protocol, pairs were composed as follows. The first

\footnotetext{
${ }^{8}$ See Appendix 1 for the complete instructions for Treatment 1 for friends protocol. Instructions for the other treatments and/or protocols are available under request.

${ }^{9}$ Another problem which appears when conducting the experiment is that we need that all pairs of friend show up for the same experimental session. Therefore, if one group of friends was composed by four friends and a member did not show up (we drop her corresponding pair in the game), the remainder members (2) could visually infer which was exactly her pair in the game.
} 
member of the pair was extracted from the two groups previously elicited in the first stage. The second member of the pair was randomly chosen from a different pool of students belonging to the School of Economics who had played the same elicitation mechanism (BCJP) several months before (for a different experiment) and also had signed up for the second phase of this experiment. In this way, we have the same (network) information of participants in both protocols. Moreover, all subjects have participated in (and therefore experienced) the same elicitation mechanism before playing the coordination game. For this protocol, also subjects who named at least 3 friends were chosen. In this way, we avoid the problem of selection bias given that the distribution of number of friends named by participants in both protocols was similar. All participants where matched with a subject randomly chosen from the pool of participants not belonging to her network (the group of class). In sum, in the "strangers" protocol, subjects (most of them had named at least 3 friends) played the game against another subject who was neither in her list of friends nor in her same class.

\subsection{Third stage: envy and questionnaire}

\subsubsection{Envy game}

This third stage was played six months after the coordination game. The experiment consist in 15 dictatorial binary decisions. Subjects had to choose between two different divisions of the money between themselves and another player in the experiment. To avoid confusion in the interpretation of the game, in- 
structions said explicitly that the division of the money was not made between friends. Pairs were formed by participants in the previous stage in the role of dictators and students recruited from a different faculty in the role of recipients. There was no reversal role, that is, subjects only played as dictators.

The structure of dictatorial decisions was taken from Charness and Rabin (2002). The idea was to analyze how envy could explain differences in subjects' behavior in the proposed coordination game for the two different matching protocols (friends vs strangers). Charness and Rabin propose a battery of dictatorial decisions in order to measure social preferences. This third part of our experiment adapts Charness and Rabin's structure with the aim of obtaining subjects' level of envy. ${ }^{10}$

Next Figure 2 displays all dictatorial binary decisions. Dictator payoff's correspond to the second coordinate of each division vector. We consider a fixed division as a start point in which the dictator is worse off than the recipient: $(600,400)$. This was always the first alternative for dictators. In the second alternative, dictators had the opportunity of obtaining more money than recipients (in relative terms), but they had to sacrifice a positive amount to get it. In sum, the first division of the money was fixed and the second division was changing in two dimensions: the amount dictator had to sacrifice (lost $=0,10$, $20,30,40)$ and the difference in payoffs between dictators and recipients $(25$, $50,75)$. In all decisions we consider that choosing the second division of the money involves envy in the Fehr-Schmidt sense. Thus, the higher the number

\footnotetext{
${ }^{10}$ See Appendix 2 for the instructions of the envy stage and the complete set of decisions subjects faced.
} 
of times choosing the second possibility, the higher the players' level of envy. ${ }^{11}$

\begin{tabular}{|l|l|l|l|}
\hline & Difference $=\mathbf{2 5}$ & Difference $=\mathbf{5 0}$ & Difference $=\mathbf{7 5}$ \\
\hline $\begin{array}{l}\text { Lost } \\
\mathbf{0}\end{array}$ & $(600,400)$ vs $(375,400)$ & $(600,400)$ vs $(350,400)$ & $(600,400)$ vs $(325,400)$ \\
\hline $\begin{array}{l}\text { Lost } \\
\mathbf{1 0}\end{array}$ & $(600,400)$ vs $(365,390)$ & $(600,400)$ vs $(340,390)$ & $(600,400)$ vs $(315,390)$ \\
\hline $\begin{array}{l}\text { Lost } \\
\mathbf{2 0}\end{array}$ & $(600,400)$ vs $(355,380)$ & $(600,400)$ vs $(330,380)$ & $(600,400)$ vs $(305,380)$ \\
\hline $\begin{array}{l}\text { Lost } \\
\mathbf{3 0}\end{array}$ & $(600,400)$ vs $(345,370)$ & $(600,400)$ vs $(320,370)$ & $(600,400)$ vs $(295,370)$ \\
\hline $\begin{array}{l}\text { Lost } \\
\mathbf{4 0}\end{array}$ & $(600,400)$ vs $(335,360)$ & $(600,400)$ vs $(310,360)$ & $(600,400)$ vs $(285,360)$ \\
\hline
\end{tabular}

Figure 2. Dictatorial binary decisions involving envy.

From the 15 decisions, players were paid only for 4 of their decisions chosen randomly. This means that subjects were paid for $25 \%$ of their decisions selected at random. This percentage of paid decisions was also taken from Charness and Rabin (2002), who run experiments in which participants made from two to eight choices and knew that they would be paid according to the outcome generated by one or two of their choices selected at random.

On average, each participant earned 15 Euros for this stage.

\footnotetext{
${ }^{11}$ There is a similar work of Charness\&Grosskopf(2001) which studies "difference aversion" and its influence on self-reported happiness with binary dictatorial decisions.
} 


\subsubsection{Questionnaire}

The last part of the experiment was a questionnaire run immediately after the envy stage, in order to obtain information about personal issues, socioeconomic variables, cognitive abilities and risk aversion. The sociodemographic variables were age, wealth (measured as the available money per week subjects have), education level of the head of the household, rooms in the house, people living in the house and number of hours of work per week.

The cognitive part, was based on three questions extracted from the work developed by Frederick (2005). We simply add the number of correct answers, in this way the cognitive index ranges from 0 to 3 for each individual.

Regarding the risk aversion part, we used the test introduced by Holt and Laury (2002). They consider a menu of ten paired lotteries in which the first lottery (safe option) always assures a higher payoff than the second (risky option). The dimension in which lotteries changed is the expected payoffs. Although expected payoffs are increasing in both lotteries, the difference between the safe and the risky lottery is also increasing. Their results show that the majority of subjects are risk averse. We obtain a similar result.

\section{$3 \quad$ Research hypothesis}

Three main hypothesis are tested in this paper:

Hypothesis 1: the existence of social relationships between subjects may have an effect on how they solve the coordination between an efficient and an 
egalitarian outcome.

First Hypothesis is motivated by the results obtained in previous experiments related to social networks. Findings obtained by Leider et al.(2006), Brañas et al. (2005) and Goeree et al. (2007) show that social relations have a significant effect on individual behavior in Dictator Games, that is, subjects are willing to donate higher amounts of money to subjects who are closer in a social network. Therefore, a natural question arises: does the cooperative (altruistic) behavior of subjects within their social network survive in competitive environments?.

Hypothesis 2: the achievement of the efficient outcome when it is "costly" for one of the players may be affected by subjects relationships.

We explore the issue of coordination in situations where one of the subjects has to incur pecuniary sacrifice for achieving the efficient equilibrium. In this case, it is not so clear that players are going to play the efficient equilibrium and therefore, results may be different. We test wether there is a difference in behavior between friends and strangers in this situation.

Hypothesis 3: the network characteristics of a subject within a network will affect her decisions in the coordination game.

We test if standard measures on social networks will affect results in the coordination game. Results in Brañas-Garza et al. (2007) show that centrality increases donations in Dictator Games. 


\section{Results}

\subsection{Costless efficient equilibrium: Friendship effect}

Table 1 contains the percentage of pairs coordinating at each equilibrium in the case of friends and strangers for Treatment 1 and 2. The table also shows the number of cases where subjects alternate (the two equilibria) and where there is not any defined pattern of coordination (No Coord.). ${ }^{12}$

\footnotetext{
${ }^{12}$ Coordination in (U, L) equilibrium is defined as both the row and column player playing strategy $\mathrm{U}$ and $\mathrm{L}$ respectively, from round 22 on (this was the maximum round where coordination was achieved in all pairs which coordinate in the efficient equilibrium, the minimum was in the first round). Coordination in (D, R) equilibrium is defined as both the row and column player playing strategy $U$ and L respectively, from round 22 on (the minimum was round 14). Alternation between the two equilibria is defined as both members of the pair playing simultaneously ( $\mathrm{U}, \mathrm{L})$ or $(\mathrm{D}, \mathrm{R})$ from round 19 on (the minimum was round 3 ).
} 
Table 1. Convergence by pairs in Treatment 1 and 2 .

\begin{tabular}{|l|l|l|l|l|l|l|}
\hline & \multicolumn{3}{|c|}{ Game 1 } & \multicolumn{3}{c|}{ Game 2 } \\
\hline & Friends & Strangers & Total & Friends & Strangers & Total \\
\hline U, L (effic.) & $16(60 \%)$ & $23(100 \%)$ & $39(78 \%)$ & $3(11 \%)$ & $9(36 \%)$ & $12(23 \%)$ \\
\hline D, R & $7(26 \%)$ & $0(0 \%)$ & $7(14 \%)$ & $3(11 \%)$ & $4(16 \%)$ & $7(13 \%)$ \\
\hline Alternate & $2(7 \%)$ & $0(0 \%)$ & $2(4 \%)$ & $9(32 \%)$ & $5(20 \%)$ & $14(26 \%)$ \\
\hline No Coord. & $2(7 \%)$ & $0(0 \%)$ & $2(4 \%)$ & $13(46 \%)$ & $7(28 \%)$ & $20(38 \%)$ \\
\hline N13 & 27 & 23 & 50 & 28 & 25 & 53 \\
\hline
\end{tabular}

Recall that in Treatment $1,(\mathrm{D}, \mathrm{R})$ is the egalitarian equilibrium and $(\mathrm{U}, \mathrm{L})$ is the efficient one. The second and third column of Table 1 give a precise and clear idea: friendship matters. The most salient result is that only $60 \%$ of pairs of friends achieve the efficient equilibrium (despite being costless for the column player) whereas the $100 \%$ of the pairs of strangers do it. This difference between friends and strangers' behavior is statistically significant with a Mann-Whitney test $(z=3.431, p-$ value $=0.001)$ Thus, the existence of previous relationships among participants do not help to achieve the efficient outcome.and therefore, Hypothesis 1 is supported.

It is remarkable that for $7 \%$ of the pairs of friends it was not possible to get any kind of coordination No any single pair of strangers fell in this sort of

\footnotetext{
${ }^{13}$ Note that the number of observations $(\mathrm{N})$ in this table refers to pairs of subjects, not to individual observations.
} 
obstinacy. However, a Mann-Whitney test does not support this idea given that the difference is not statistically significant $(z=-1.319, p-$ value $=0.187)$.

\subsection{Costly efficient equilibrium: Friendship effect}

The three last columns of Table 1 contain results for Treatment 2. Recall that we have two different equilibria, one of them efficient, (U, L) and the other one with unequal payoffs, (D, R).

Results show that the percentage of pairs of strangers playing the efficient equilibrium nearly triples the percentage of pairs of friends playing the same equilibrium. The difference is statistically significant with a Mann-Whitney test $(z=2.175, p-$ value $=0.030)$. Therefore, Hypothesis 2 is supported, that is, friends and strangers behave differently in the search of the efficient outcome when it is costly.

Another salient feature of this setting is that friends miscoordinate more frequently than strangers do (47\% versus $29 \%$ ) but the difference is not significant, again using a Mann-Whitney test $(z=-1.369, p-$ value $=0.171)$. Thus, we may conclude that friendship does not erase (even increase) miscoordination.

The percentage of pairs coordinating in the inefficient equilibrium is the same in both matching protocols. Results also show that the percentage of friends alternating equilibria is slightly higher than for strangers. 


\subsection{Costless versus costly efficient equilibrium}

We explore the role of the "price" of sacrifice by merging data from both matching protocols (friends and strangers). This analysis is in line with the work of Andreoni and Miller (2002) in Dictator Games. The fourth column total (costless) in Table 1 contains aggregated (by matching protocol) data from Treatment 1 and the last column total (costly) for Treatment 2 .

It is patent that costless helping enormously facilitates coordination at the efficient outcome. Results are clear: There are very few pairs coordinating in the efficient outcome in Treatment 2. Since in this treatment column players must sacrifice own payoffs to achieve efficiency, this result is quite sensitive. Differences in behavior between the two treatments are highly significant $(z=$ $-5.589, p-$ value $=0.000)$.

This result is not very surprising. Subjects value the cost of their actions. Note that our results, although in strategic settings, are analogous to the evidence on the relative price of altruism (see Andreoni and Miller (2002)).

Regarding other kind of coordination, an evident fact is that alternation of the two equilibria only arises in Treatment 2 when each player highest payoffs are reached in a different equilibrium. A Mann-Whitney test on the difference between the two treatments in alternating equilibria confirms that it is significant $(z=3.124, p-$ value $=0.002)$. This evidence is in line with other experiments on coordination in symmetric Battle of the Sexes in which alternation of equilibrium is one of the patterns observed (see for instance Mckelvey and Palfrey (2001) and Andalman and Kemp (2004) among others). 
The percentage of miscoordination is notably higher in Treatment 2 . The differences are significant at a $1 \%$ level $(z=-4.155, p-$ value $=0.000)$. The conflict in the "costly" treatment seems to be stronger than in the "costless" one.

Surprisingly, the coordination in the inefficient equilibrium is similar in both treatments. This may be due to the fact that the percentage lost in coordination in the efficient outcome in the costly treatment respect to the costless one, is shared between the inefficient outcome and the alternation of the two equilibria.

To sum up, this paper gives evidence on how friendship may drive coordination. Our experiment provides two clear results. On one hand, friends are less prone to coordinate in the efficient outcome than strangers do. On the other hand, friends are more prone to miscoordinate than strangers do.

One of the natural explanations we can give for these results is envy. We consider that envy has much more sense with acquaintances than in pure-stranger settings. In fact, interpersonal comparisons are more habitual among peers. We analyze this explanation in more detail in the next section, when we study how envy game results are related to efficiency in the coordination game.

\subsection{Group behavior}

In this section we develop an econometric analysis from the point of view of the fixed pairs who played the coordination game.

We consider a Bivariate Probit Model $^{14}$. Thus, we want to estimate the joint

\footnotetext{
${ }^{14}$ As we expected to observe a higher percentage of ones (efficient strategy) than zeros, we
} 
probability that a pair (row and column player) of subjects plays the efficient equilibrium:

$$
P\left(\mathbf{y}_{i}^{R}=1, \mathbf{y}_{i}^{C}=1, \mid X_{i}\right)
$$

where $\mathbf{y}_{i}^{R}\left(\mathbf{y}_{i}^{C}\right)$ is the decision taken by the row (column) player which takes the value 1 if the strategy chosen is $\mathrm{U}(\mathrm{L})$ and 0 otherwise and $X_{i}$ is a matrix which contains the set of independent variables. The two equations which determine the model may be specified as follows.

$P\left(\mathbf{y}_{i}^{R}=1, \mathbf{y}_{i}^{C}=1, \mid X_{i}\right)=P\left(\boldsymbol{\epsilon}_{i}^{R}>-X_{i} \boldsymbol{\beta}^{R}, \boldsymbol{\epsilon}_{i}^{C}>-X_{i} \boldsymbol{\beta}^{C}\right)=\boldsymbol{\Phi}_{\left(\boldsymbol{\epsilon}_{i}^{R}, \boldsymbol{\epsilon}_{i}^{C}\right)}\left(X_{i} \boldsymbol{\beta}^{R}, X_{i} \boldsymbol{\beta}^{C}\right)$

where $\boldsymbol{\beta}^{R}\left(\boldsymbol{\beta}^{C}\right)$ is the vector of coefficients estimated for the decision of the row (column) player, $\boldsymbol{\epsilon}_{i}^{R}, \boldsymbol{\epsilon}_{i}^{C}$ are the errors associated to each equation which are distributed according to a the distribution, $\boldsymbol{\Phi}_{\left(\epsilon_{i}^{R}, \boldsymbol{\epsilon}_{i}^{C}\right)}$, of a bivariate normal. As in our sample could be problems or heterokedasticity we have run regressions with robust errors allowing for difference in variance between subjects. In addition, we consider a cluster in observations from the same group of subjects, that is the 25 observations from different rounds. To control for time effects in the dependent variable we have consider dummies for all 25 rounds and there are not important changes in coefficients and significance levels of independent variables.(PONER FOOTNOTE SOBRE EL RHO, LAURA CRESPO)

Regarding the choice of the dependent variable, the reason why we decided

have chosen the probit model. 
to estimate jointly the decision of both players in the efficient equilibrium is as follows. The aim of this paper is to analyze how social networks influence efficiency (measure as the sum of payoffs) in coordination games. Only in the case that both players in the pair are playing the efficient strategy, they reach the efficient equilibrium. At the moment that one of the players decides to move from this efficient strategy, the outcome is not efficient. Instead of taking only two options, efficient or not, we could establish a range of efficiency in terms of the sum of payoffs. We decided not to do so because we consider that, once a member of the pair is not playing the efficient strategy, the fact that the sum of payoffs is greater in some specific cell, is due to the structure of the game (not to efficiency).

As explanatory variables we consider: the treatment, the matching protocol (friend vs stranger), clustering, betweenness, degree in and degree out, envy, risk aversion, wealth, education level of the family head, number of rooms per capita in players's house and cognitive abilities. We consider that interactions between the treatment and the matching protocol were interesting to analyze. ${ }^{15}$

The set of variables related with social networks were obtained from the networks elicited in the first stage of the experiment. In what follows we briefly described them. The clustering of a given node $i$ is defined as the fraction of pairs of neighbors of $i$ that are themselves neighbors. The rank of clustering is

\footnotetext{
${ }^{15}$ The following variables are dummies: Treat $j^{*}$ Friend $=1$ when the observation is from Treatment $j$ and Friend matching protocol, $j=1,2$, Treat $j^{*}$ Stranger $=1$ when the observation is from Treatment $j$ and Stranger matching protocol, $j=1,2$. We dropped Treat $1 *$ Stranger to avoid perfect multicollinearity. The last dummie, Column $=1$ when the subject has the role of column player.
} 
$[0,1]$. The betweenness centrality of a node $i$ is defined as the fraction of all shortest paths connecting any two nodes $j$ and $k$ which also pass through $i$ from the set of all shortest paths connecting any two nodes $j$ and $k$. Degree out (in) is the number of links sent (received) by a node. ${ }^{16}$

For risk aversion, as explained in section 2.4, subjects had to take decisions in the set of lotteries proposed by Holt and Laury (2002). Once we have the decisions for the whole set of lotteries, we add the number of safety decisions taken by each player. This number give us an individual measure of risk aversion.

Envy is obtained in a similar way as risk aversion. Subjects faced a battery of 15 binary dictatorial decisions as explained in section 2.3. Once we have the information about subjects behavior for the 15 cases, we give to each binary decision value 1 if it was motivated by envy and value 0 otherwise. We add all the values obtained for each subject and we obtain an index of the individual level of envy (rank from 0 to 15). Cognitive abilities, wealth, education level of the family head, and the number of rooms per capita in players's house are obtained directly from the questionnaire. Observe that explanatory variables are duplicated because we consider each variable for the row and for the column player. ${ }^{17}$ For instance, we have two variables which refer to each network measure: betweenness_row, betweenness_column and so on.

Next table 2 displays results of three bivariate probit regressions on the frequency of the efficient equilibrium, (U, L) played by pairs. The first three

\footnotetext{
${ }^{16}$ We computed these network measures using pajek software.

${ }^{17}$ In this way, we do not have to lose any information computing for each explanatory variable a new value that captures both the row and the column player effect (for instance, the mean of both variables).
} 
regressions contain coefficients estimated for the first equation of the biprobit model, that is for the dependent variable being the row player decision $\left(y^{R}\right)$. The last three colums of Table 2 correspond to the second equation, that is, the case in which the dependent variable is the column player decision $\left(y^{C}\right)$. Note that the numbers in each cell are not marginal effects but coefficients. ${ }^{18}$

\footnotetext{
${ }^{18}$ Note that there are only 3 different regressions. However as the model is bivariate, there are 2 equations for each regression, that is the reason why there are 6 columns in Table 2 .
} 
Table 2. Bivariate Probit regressions on the frequency of efficient equilibrium (U,L).

\begin{tabular}{|c|c|c|c|c|c|c|}
\hline \multirow[b]{2}{*}{ Indep. vble } & \multicolumn{6}{|c|}{ Dependent variable } \\
\hline & $\begin{array}{c}(1) \\
y^{R}=1\end{array}$ & $\begin{array}{c}(2) \\
y^{R}=1\end{array}$ & $\begin{array}{c}(3) \\
y^{R}=1\end{array}$ & $\begin{array}{c}(1) \\
\mathrm{y}^{\mathrm{C}}=1\end{array}$ & $\begin{array}{c}(2) \\
y^{C}=1\end{array}$ & $\begin{array}{c}(3) \\
y^{C}=1\end{array}$ \\
\hline Envy_row & $\begin{array}{l}-\mathbf{- 0 . 1 9 3} * * \\
(0.082)\end{array}$ & & $\begin{array}{c}\mathbf{- 0 . 2 0 2} * * \\
(0.082)\end{array}$ & $\begin{array}{l}\mathbf{- 0 . 1 6 5} * * \\
(0.069)\end{array}$ & & $\begin{array}{c}-\mathbf{- 0 . 2 7 5} * * * * \\
(0.069)\end{array}$ \\
\hline Envy_col & $\begin{array}{l}\mathbf{- 0 . 1 0 0} * * * * \\
(0.030)\end{array}$ & $\begin{array}{c}-\mathbf{- 0 . 0 6 2} * \\
(0.032)\end{array}$ & $\begin{array}{c}-\mathbf{- 0 . 0 6 7} * * \\
(0.032)\end{array}$ & $\begin{array}{l}\mathbf{- 0 . 1 1 2} * * * * \\
(0.031)\end{array}$ & $\begin{array}{l}-\mathbf{- 0 . 0 9 4} * * * * \\
(0.032)\end{array}$ & $\begin{array}{l}\mathbf{- 0 . 1 2 1} * * * * \\
(0.029)\end{array}$ \\
\hline Risk avers_row & $\begin{array}{c}-\mathbf{0 . 0 5 3} * \\
(0.029)\end{array}$ & $\begin{array}{l}-0.028 \\
(.030)\end{array}$ & $\begin{array}{c}-0.042 \\
(.026)\end{array}$ & $\begin{array}{c}-0.025 \\
(.028)\end{array}$ & $\begin{array}{c}-0.011 \\
(.027)\end{array}$ & $\begin{array}{l}-0.008 \\
(.025)\end{array}$ \\
\hline Risk avers_col & $\begin{array}{l}-0.063 \\
(0.042) \\
\end{array}$ & $\begin{array}{c}-0.052 \\
(0.043) \\
\end{array}$ & $\begin{array}{c}-0.059 \\
(0.044) \\
\end{array}$ & $\begin{array}{c}-0.039 \\
(0.040)\end{array}$ & $\begin{array}{l}-0.033 \\
(0.041)\end{array}$ & $\begin{array}{l}-0.015 \\
(0.045)\end{array}$ \\
\hline Cognitive_row & $\begin{array}{l}\mathbf{0 . 6 5 3} * * * \\
(0.146)\end{array}$ & $\begin{array}{l}\mathbf{0 . 5 3 7} * * * * \\
(0.170)\end{array}$ & $\begin{array}{l}\mathbf{0 . 5 3 2} * * * * \\
(0.172)\end{array}$ & $\begin{array}{l}\mathbf{0 . 5 4 5}^{* * * *} \\
(0.156)\end{array}$ & $\begin{array}{l}\mathbf{0 . 4 9 4} * * * * \\
(0.173)\end{array}$ & $\begin{array}{c}\mathbf{0 . 8 0 4} * * * * \\
(0.183)\end{array}$ \\
\hline Cognitive_col & $\begin{array}{l}0.214 \\
(0.154)\end{array}$ & $\begin{array}{c}0.296 \\
(0.183)\end{array}$ & $\begin{array}{c}0.245 \\
(0.177)\end{array}$ & $\begin{array}{l}\mathbf{0 . 3 0 9} * \\
(0.170)\end{array}$ & $\begin{array}{l}\mathbf{0 . 4 2 9} * * \\
(0.192)\end{array}$ & $\begin{array}{r}\mathbf{0 . 4 0 6}^{* * *} \\
(0.191)\end{array}$ \\
\hline Between_row & $\begin{array}{l}\text { 81.949**** } \\
(29.252)\end{array}$ & $\begin{array}{r}\mathbf{4 7 . 8 0 9} * * \\
(27.757)\end{array}$ & & $\begin{array}{l}\mathbf{9 6 . 9 3 5 * * * *} \\
(34.399)\end{array}$ & $\begin{array}{c}\mathbf{8 7 . 3 4 9} * * * * \\
(32.464)\end{array}$ & \\
\hline Between_col & $\begin{array}{l}\mathbf{1 4 . 2 6 3}^{* * *} \\
(6.789)\end{array}$ & $\begin{array}{l}\mathbf{1 5 . 6 2 2} * * * \\
(6.920)\end{array}$ & & $\begin{array}{l}\text { 23.084**** } \\
(7.183)\end{array}$ & $\begin{array}{l}\mathbf{2 4 . 5 2 9} * * * * \\
(6.731)\end{array}$ & \\
\hline Degree in_row & $\begin{array}{l}\text { 0.300*** } \\
(0.105)\end{array}$ & & & $\begin{array}{c}0.103 \\
(0.135)\end{array}$ & & \\
\hline Degree in_col & & & $\begin{array}{l}\mathbf{0 . 0 6 6}^{* * * * *} \\
(0.151)\end{array}$ & & & $\begin{array}{c}\mathbf{0 . 2 6 0 *} \\
(0.148)\end{array}$ \\
\hline Degreeout_row & & & $\begin{array}{l}0.126 \\
(0.126)\end{array}$ & & & $\begin{array}{c}\mathbf{0 . 4 6 7} * * * * \\
(0.122)\end{array}$ \\
\hline Degreeout_col & & & $\begin{array}{l}0.102 \\
(0.110)\end{array}$ & & & $\begin{array}{c}\mathbf{- 0 . 2 5 8} \text { *** } \\
(0.118)\end{array}$ \\
\hline Clustering_row & & $\begin{array}{l}\mathbf{- 2 . 9 4 4} * * \\
(1.172)\end{array}$ & & & $\begin{array}{c}\mathbf{- 3 . 2 9 1} \text { *** } \\
(1.291)\end{array}$ & \\
\hline Clustering_col & & & $\begin{array}{l}\mathbf{- 3 . 3 5 9} * * * * \\
(1.035)\end{array}$ & & & $\begin{array}{c}\mathbf{- 5 . 1 3 5} * * * * \\
(1.074) \\
\end{array}$ \\
\hline Treat $2 *$ Friend & $\begin{array}{l}\mathbf{- 1 . 9 9 7} * * * \\
(0.477)\end{array}$ & $\begin{array}{c}\mathbf{- 1 . 9 2 6} * * * * \\
(0.434)\end{array}$ & $\begin{array}{l}\mathbf{- 1 . 8 2 1} * * * \\
(0.461)\end{array}$ & $\begin{array}{c}\mathbf{- 1 . 8 7 1} * * * * \\
(0.443)\end{array}$ & $\begin{array}{c}\mathbf{- 2 . 0 6 9} \text { **** } \\
(0.403)\end{array}$ & $\begin{array}{c}\mathbf{- 1 . 7 8 9} * * * * \\
(0.471)\end{array}$ \\
\hline Treat $1 *$ Friend & $\begin{array}{l}\mathbf{- 1 . 2 5 4} * * * \\
(0.392)\end{array}$ & $\begin{array}{r}-\mathbf{0 . 9 0 6 * *} \\
(0.374)\end{array}$ & $\begin{array}{c}-1.110 * * * \\
(0.358)\end{array}$ & $\begin{array}{l}\mathbf{- 0 . 7 5 8}^{*} \\
(0.406)\end{array}$ & $\begin{array}{c}-\mathbf{0 . 8 6 6} * * \\
(0.356)\end{array}$ & $\begin{array}{r}\mathbf{- 1 . 0 2 2} * * \\
(0.414)\end{array}$ \\
\hline Treat $2 *$ Strang & $\begin{array}{c}\mathbf{- 1 . 8 1 2 * * *} \\
(0.412)\end{array}$ & $\begin{array}{r}-\mathbf{1 . 9 1 4} * * * * \\
(0.393)\end{array}$ & $\begin{array}{c}\mathbf{- 1 . 8 4 2} \text { **** } \\
(0.550)\end{array}$ & $\begin{array}{l}\mathbf{- 1 . 4 6 1 * * *} \\
(0.386)\end{array}$ & $\begin{array}{r}-\mathbf{1 . 7 2 3} * * * * \\
(0.328)\end{array}$ & $\begin{array}{r}\mathbf{- 1 . 7 5 0} * * * * \\
(0.478)\end{array}$ \\
\hline Wealth_row & $\begin{array}{c}0.002 \\
(0.004)\end{array}$ & $\begin{array}{l}0.001 \\
(0.004)\end{array}$ & $\begin{array}{c}0.006 \\
(0.005)\end{array}$ & $\begin{array}{l}0.005 \\
(0.005)\end{array}$ & $\begin{array}{c}-0.001 \\
(0.004)\end{array}$ & $\begin{array}{l}\mathbf{0 . 0 1 2}^{*} \\
(0.006)\end{array}$ \\
\hline Wealth_col & $\begin{array}{c}-0.002 \\
(0.002)\end{array}$ & $\begin{array}{c}-0.002 \\
(0.002)\end{array}$ & $\begin{array}{l}0.001 \\
(0.001)\end{array}$ & $\begin{array}{c}-0.002 \\
(0.002)\end{array}$ & $\begin{array}{c}-0.003 \\
(0.002)\end{array}$ & $\begin{array}{l}\mathbf{0 . 0 0 4} * * * \\
(0.001)\end{array}$ \\
\hline $\begin{array}{l}\text { Educ. Family } \\
\text { head_row }\end{array}$ & $\begin{array}{l}\text { 0.198* } \\
(0.112)\end{array}$ & $\begin{array}{c}\mathbf{0 . 2 3 9} * * \\
(0.102) \\
\end{array}$ & $\begin{array}{r}0.139 \\
(0.119) \\
\end{array}$ & $\begin{array}{l}0.040 \\
(0.134)\end{array}$ & $\begin{array}{c}0.086 \\
(0.128)\end{array}$ & $\begin{array}{l}0.085 \\
(0.137)\end{array}$ \\
\hline $\begin{array}{l}\text { Educ. Family } \\
\text { head_col }\end{array}$ & $\begin{array}{l}-0.162 \\
(0.138)\end{array}$ & $\begin{array}{l}-0.028 \\
(0.134)\end{array}$ & $\begin{array}{l}-0.102 \\
(0.135)\end{array}$ & $\begin{array}{l}-\mathbf{0 . 2 9 8} * * \\
(0.139)\end{array}$ & $\begin{array}{l}-0.203 \\
(0.127)\end{array}$ & $\begin{array}{l}-0.138 \\
(0.139)\end{array}$ \\
\hline $\begin{array}{l}\text { Rooms per } \\
\text { capita_row }\end{array}$ & $\begin{array}{l}0.294 \\
(0.190)\end{array}$ & $\begin{array}{c}-\mathbf{0 . 3 2 1} * \\
(0.172) \\
\end{array}$ & $\begin{array}{c}0.275 \\
(0.174) \\
\end{array}$ & $\begin{array}{l}0.247 \\
(0.174) \\
\end{array}$ & $\begin{array}{r}0.129 \\
(0.155) \\
\end{array}$ & $\begin{array}{c}0.227 \\
(0.171) \\
\end{array}$ \\
\hline $\begin{array}{l}\text { Rooms per } \\
\text { capita_col }\end{array}$ & $\begin{array}{c}0.073 \\
(0.181)\end{array}$ & $\begin{array}{c}0.130 \\
(0.223)\end{array}$ & $\begin{array}{l}-0.016 \\
(0.175)\end{array}$ & $\begin{array}{l}-0.064 \\
(0.189)\end{array}$ & $\begin{array}{l}-0.055 \\
(0.209)\end{array}$ & $\begin{array}{l}-0.194 \\
(0.172)\end{array}$ \\
\hline Hrs work_row & $\begin{array}{l}-0.013 \\
(0.080)\end{array}$ & $\begin{array}{l}-0.106 \\
(0.082)\end{array}$ & $\begin{array}{c}-0.034 \\
(0.074)\end{array}$ & $\begin{array}{l}\mathbf{- 0 . 1 9 9} * * * \\
(0.089)\end{array}$ & $\begin{array}{r}-\mathbf{0 . 2 3 7} * * \\
(0.093)\end{array}$ & $\begin{array}{l}-0.142 \\
(0.100)\end{array}$ \\
\hline Hrs work_col & $\begin{array}{l}-0.122 \\
(0.079)\end{array}$ & $\begin{array}{l}-0.081 \\
(0.084)\end{array}$ & $\begin{array}{l}-0.065 \\
(0.076)\end{array}$ & $\begin{array}{l}-0.007 \\
(0.062)\end{array}$ & $\begin{array}{c}-0.003 \\
(0.067)\end{array}$ & $\begin{array}{l}0.025 \\
(0.065)\end{array}$ \\
\hline $\mathrm{N}$ & 1525 & 1525 & 1525 & 1525 & 1525 & 1525 \\
\hline
\end{tabular}

For the econometric analysis we consider three different groups of indepen-

dent variables due to the correlation among them. ${ }^{19}$

\footnotetext{
${ }^{19}$ We found that explanatory variables envy and clustering_column, degree in_row and degree in_column, betweenness_row(column) and degree out_row(column), betweenness_row and clustering row, degree in row and clustering row are correlated two by two. We conclude that from the following analysis. For pairwise partial correlation coefficients higher than
} 
Results in Table 2 show that the variable friend has a negative and statistically significant effect on the frequency of reaching the efficient equilibrium when players are playing Treatment 1 (efficient versus egalitarian equilibrium). This effect is also negative and significant when subjects are playing Treatment 2. This result is not unexpected given results shown in previous sections 4.1 and 4.2. If we compute marginal effects, we obtain that the negative effect of Treatment 2 (costly) is larger than that of Treatment 1 (also supported by tests of hypothesis of previous section 4.3).

Regarding network measures, the regressions show that while the betweenness (for both types of players) has a positive and statistically significant effect on the efficient outcome. The variable degree out is only significant for the efficient choice of column player and the effect is positive. Degree in is only significant for the corresponding type of player, that is degree in of row player only affects positively its own choice of the strategy which leads to the efficient equilibrium. Finally, the level of clustering (for both row and column) has a negative and statistically significant effect on the probability of obtaining the efficient equilibrium. All these results give support for Hypothesis 3.

Clustering of an individual may be interpreted as the cohesiveness of the group of friends of that individual. One possible explanation for the negative effect of clustering is that subjects who have a high percentage of friends which

0.4 , we consider a regression in which all independent variables are significant, including only one of the variables which may be correlated (for instance clustering_row). Then, we run a new regression adding the variable (degree in_row) which is possibly correlated with the first one. If the original variable (clustering_row) turns to be not significant in the new regression, we deduce that those two variables are correlated. 
are friends among them, must have a conciliatory and fair nature in order to mediate in conflicts. In this setting, the less conflictive outcome is the one with more equal payoffs, $(\mathrm{D}, \mathrm{R})$, so players with higher clustering will play in this way and be less efficient.

The remainder network variables, degree out, degree in and betweenness, may be interpreted as social integration of an individual within the network. Thus, we may conclude that social integration affects positively efficiency.

The effect of the sociodemographic variables obtained in the questionnaire is not very significant in most of the regressions. Cognitive abilities have a positive and significant effect on pairs' efficient behavior. ${ }^{20}$

The effect of level of risk aversion of subjects (row and column) is not statistically significant (except in one case in which the significance is very weak). We expected this result since we designed the payoff tables for strategic uncertainty to vanish. Results show that the way we controlled strategic uncertainty actually works.

Finally, the level of envy for both column and row players, plays a negative and significant role on the frequency of playing the efficient equilibrium. If we run a Chow test for comparing the effect of envy on playing the efficient equilibrium between friends and stranger, we find that we reject the null hypothesis of equality of marginal effects $\left(\chi^{2}(1)=0.09, p-\right.$ value $=0.381$, one-sided test $)$ for

\footnotetext{
${ }^{20}$ From all sociodemographic variables there are many of them that are correlated as: $\{$ age, course, hours of work $\}$, \{number of rooms, people living at home $\}$, \{education level of the family head, work of the family head $\}$. Given that most of them are not significant we have chosen a group of them that are not correlated or interactions between correlated variables for not presenting a too high number of different regressions.
} 
all regressions considered in Table $2 .{ }^{21}$ Thus, the explanation that envy is more important for friends than for strangers and it causes the efficient equilibrium to be played more frequently for strangers than for friends is supported by the data.

\section{Conclusions}

Results show that pairs of strangers playing the game reach a more efficient outcome than pairs of friends, showing that not only positive values arise from social relationships. Wether Dawes, van de Kragt, and Orbell (1988), Brewer and Brown (1998) show that group identification may cause people to place group's interests above their own, or Billig, Bundy, Flament and Tajfel (1971) and Brañas et al. (2005) find that subjects strongly favor members of their experimental ingroup, our paper clearly contradicts this evidence.

Regarding social preferences, our results show that envy may be more significant for "friends" than for "strangers". Therefore, this suggest that the well-known utility function by Fehr and Schmidt (1999) may be extended making the parameters which measure envy and guilty depending on the level of relationship with the other players involved in the game.

This work may be seen as an starting point for applying this methodological approach to more complex economic environments. To the best of our knowledge, no paper has analyzed the effect of social networks on non-strategic

\footnotetext{
${ }^{21}$ The p-value reported here is the minimum of the three regressions considered in Table 2.
} 
settings. On one hand, the structure of the network may play an important role on the efficiency for instance. Thus, it will be interesting to study which is the effect of social networks on the final outcome of classic strategic games such us Prisoner's Dilemma, Ultimatum game, Public Good games and so on. On the other hand, standard results obtained in experiments may change if subjects play with friends or acquaintances (instead of strangers). The latter will be more appropriate for experiments involving social preferences. 


\section{References}

[1] Andalman A. \& C. Kemp (2004) "Alternation in the repeated Battle of the Sexes", MIT Press.

[2] Andreoni, J. (1988) "Why free ride? Strategies and learning in public good experiments". Journal of Public Economics 37 (3), 291-304.

[3] Andreoni J. \& J. Miller (1993) "Rational Cooperation in the Finitely Repeated Prisoner's Dilemma: Experimental Evidence", The Economic Journal, Vol. 103, No. 418, pp. 570-585.

[4] Andreoni J. \& J. Miller (2002) "Giving according to GARP: An experimental test of the consistency of preferences for altruism", Econometrica $70,737-753$.

[5] Billig M., R. P. Bundy, C. Flament \& H. Tajfel (1971), "Social categorization and intergroup behavior," European Journal of Social Psychology, 1, $149-178$.

[6] Bohnet, I. \& B. Frey (1999) "Social Distance and Other-Regarding Behavior in Dictator Games: Comment". The American Economic Review 89, 335-339.

[7] Brañas-Garza, P., R. Cobo-Reyes, N. Jiménez, M.P. Espinosa \& G. Ponti (2007) "Altruism in the (Social) Network". Mimeo. 
[8] Brañas, P., R. Cobo-Reyes \& A. Domínguez (2006a), "Si él lo necesita": Gypsy fairness in Vallecas. Experimental Economics sp. issue on Behavioral Economics [eds.: C. Camerer \& R. Weber] 9(3): 253-264.

[9] Brañas, P., R. Cobo-Reyes, N. Jimenez \& G. Ponti (2006b), "Psychological Games and Social Networks: a 'Privacy-Respectful' Elicitation Device Based on Guilt Aversion". Mimeo.

[10] Brañas-Garza P., M. A. Durán \& M. P. Espinosa (2005) "Do experimental subjects favor their friends?". ThE Papers 05/14, Department of Economic Theory and Economic History of the University of Granada.

[11] Brewer, M. B. \& R. J. Brown (1998) "Intergroup relations. In D. T. Gilbert, S. T. Fiske \& G. Lindzey (Eds.), The handbook of social psychology. Vol. 2, pp 554-594. Boston: McGraw-Hill.

[12] Brown-Kruse, J., \& D. Hummels (1993) "Gender Effects in Laboratory Public Goods Contribution: Do Individuals Put Their Money Where Their Mouth Is?" Journal of Economic Behavior and Organization, 22(3), 25567.

[13] Cadsby, C. \& E. Maynes (1998) "Gender and Free Riding in a Threshold Public Goods Game: Experimental Evidence." Journal of Economic Behavior and Organization, 34(4), 603-20.

[14] Charness, G. \& M. Rabin (2002) "Understanding Social Preferences with simple tests" Quarterly Journal of Economics 117: 817-869. 
[15] Croson, R., M. Marks and J. Snyder (2003) "Groups Work for Women: Gender and Group Identity in the Provision of Public Goods". Mimeo.

[16] Dawes, R. M., A. J. C. van de Kragt \& J. M. Orbell, (1988) "Not me or thee but we: The importante of group identity in eliciting cooperation in dilemma situations". Experimental manipulations. Acta Psychologica, 68, 83-97.

[17] Fehr E. and K. Schmidt (1999) "A Theory of Fairness, Competition and Cooperation". The Quarterly Journal of Economics 114, 817-868.

[18] Fischbacher, U. (2007) "Ztree: Zurich Toolbox for Ready-made Economic Experiments". Experimental Economics, 10(2): 171-178.

[19] Frederick, S. (2005) "Cognitive Reflection and Decision Making", Journal of Economic Perspectives, 19(4), 24-42.

[20] Fudenberg, D. y D. K. Levine: "The Theory of Learning in Games", MIT Press, 1998.

[21] Goeree, J.K., M. McConell, T. Mitchell, T. Tromp \& L. Yariv (2007) "Linking and giving among teenage girls". Mimeo.

[22] Gonzalez L. G. , W. Güth \& M. V. Levati (2005) "When does the game end? Public goods experiments with non-definite and non-commonly known time horizons". Economics Letters, 88, 221-226.

[23] Harsanyi, J.C. and Selten, R. (1988) A General Theory of Equilibrium Selection in Games. MIT Press Cambridge. 
[24] Henrich, J (2000). "Does culture matter in economic behavior? Ultimatum game bargaining among the Machiguenga". American Economic Review, 90(4): 973-979.

[25] Hoffman, E., K. McCabe, K. Schachat, \& V. Smith (1994) "Preferences, Property Rights, and Anonymity in Bargaining Games", Games and Economic Behavior 7, 346-80.

[26] Hoffman, E., K. McCabe \& V. Smith (1996) "Social Distance and OtherRegarding Behavior" American Economic Review, 86, pp. 653-660.

[27] Holt, C. A. \& S. K. Laury (2002) "Risk Aversion and Incentive Effects" American Economic Review, 92(5), 1644-55.

[28] Kazdin, A. E. (2000) "Encyclopedia of Psychology". American Psychological Association.

[29] Kirkwood, N. \& J. L. Solow (2002), "Group identity and gender in public goods experiments". Journal of Economic Behavior \& Organization, Vol. $48,403-412$.

[30] Leider, S., M. Mobius, Rosenblat, T. and Quoc-Anh. (2006) ,"Directed Altruism and Enforcement in Social Networks". Mimeo.

[31] McKelvey R. D. \& T. R. Palfrey (2001), "Playing in the dark: Information, learning and coordination in repeated games". Technical report, California Institute of Technology. 
[32] Schmidt, D., R. Shupp, J. M. Walker and E. Ostrom (2003), "Playing safe in coordination games: the roles of risk dominance, payoff dominance, and history of play" Games and Economic Behavior 42, 281-299.

[33] Selten, R. \& R. Stoecker (1986), "End behavior in sequences of finite Prisoner's Dilemma supergames: A learning theory approach", Journal of Economic Behavior and Organization 7, 47-70.

[34] Van Huyck, J. B, R. C. Battalio \& R. O. Beil (1990)"Tacit Coordination Games, Strategic Uncertainty, and Coordination Failure" American Economic Review, 80(1), 234-248.

[35] . Van Huyck J., R. C. Battalio \& F. Rankin, (1996) "On the Evolution of Convention: Evidence from Coordination Games", Levine's Working Paper Archive 548, UCLA Department of Economics. 


\section{Appendix 1: experimental instructions I}

Welcome to the experiment!

This is an experiment to study how people solve decision problems.

Our goal is to see how people act on average; not what you, particularly, do. Do not think, then, that we expect you to perform some concrete behavior.

But, on the other hand, take into account that your behavior will affect the amount of money you will earn throughout the experiment.

This sheet contains the instructions explaining the way the experiment works.

Please do not converse with the other participants during the experiment. If you need any help, please, raise your hand and wait in silence. We will attend to you as soon as is possible.

The experiment is described as follows. In this experiment each of you will be divided randomly in groups of 2 people. There will be 2 types in this experiment: player 1 and player 2. You will be assigned one of these types randomly. You will not know who will be in your group either during or after the experiment. The only information you have is that you will play with some of the persons you named in the previous experiment, but you do not know who this person is specifically.

You will play the game shown in the table below. In this game, Player 1 and Player 2 will choose separately which strategy A or B they prefer to play. Both players will take their decisions simultaneously.

Each player makes points depending on how she played and how her partner played Numbers in payoff table correspond to the points players may get in 
each particular situation. Player 1's payoffs are in the above left corner in each cell. Player 2's payoffs are in the below right corner of the cell. At the end of the experiment, points accumulated will be converted to money at the rate 1 point $=10$ eurocents. You will play 25 rounds and your role and your partner will be FIXED along the experiment.

After each round the following information will be shown: 1) your decision in this round, 2) your partner's decision in this round, 3) you payoff in this round and 4) your total payoffs up to this round.

Player 2

\begin{tabular}{|l|l|l|l|l|}
\hline & \multicolumn{3}{|c|}{ A } & \multicolumn{2}{|c|}{ B } \\
\hline \multirow{2}{*}{ Player 1 A } & & & & \\
\hline & B & 7 & 4 & \\
\hline
\end{tabular}

For example, if player 1 chooses strategy A and Player 2 chooses strategy A, points obtained by Player 1 in this period are 8 and points obtained by Player 2 are 4. A different example: if player 1 chooses strategy A and Player 2 chooses strategy B, points obtained by Player 1 in this period are 3 and points obtained by Player 2 are 3

Summarizing: 
- You will play 25 rounds of the game shown in the above table.

- Your role will be fixed for all the experiment. Your role will be assigned randomly.

- You only know which is your role. You also know that your partner is one of the persons named in the previous experiment, but you do not know which specific person.

- In each round you must decide between strategy A or B.

- After each round you will be informed about your decision, your partner's decision, your payoffs in this round and your total payoffs.

-1 point $=10$ eurocents

- At the end of the experiment we will pay you according to the points obtained in all 25 rounds. 


\section{Appendix 2: experimental instructions II}

Welcome to the experiment!

This is an experiment to study how people solve decision problems.

Our goal is to see how people act on average; not what you, particularly, do.

Do not think, then, that we expect you to perform some concrete behavior.

But, on the other hand, take into account that your behavior will affect the amount of money you will earn throughout the experiment.

This sheet contains the instructions explaining the way the experiment works.

Please do not converse with the other participants during the experiment. If you need any help, please, raise your hand and wait in silence. We will attend to you as soon as is possible.

The experiment is described as follows. You have to decide which option you prefer between the two possibilities that will appear in the screen of your computer. Each possibility refers to a particular division of the money between yourself and another person. This person is not one of the people you named in your list of friends of the previous experiment neither a student from the Economic Faculty. What you will see in your screen has a similar structure to this example:

Option 1: $\quad(400,600)$

Option 2: $\quad(375,250)$ 
Your task will be only to choose which of the options proposed you prefer.

In this specific example Option 1 implies that you will get 400 points and your partner will receive 600 points. In Option 2, you obtain 375 points and your partner receives 250 points.

You will take this decision 15 times, with different options that will appear in your screen. From the 15 decisions we will pay you only for 4 decisions randomly chosen. That is, you will take 15 decisions, from those the computer will select 4 at random and you will be paid according to how you played in those particular situations.

The conversion rate is 100 points $=1$ euro. If you have some questions, please raise your hand. 